\title{
Basosquamous Carcinoma of Nose: A Rare Tumor Diagnosed On Cytology
}

\author{
Manupriya Sharma $^{1 *}$, Suman Singh ${ }^{1}$, Rashmi Kaul ${ }^{1}$ and V K Mahajan ${ }^{2}$ \\ ${ }^{1}$ Dept of Pathology, Dr RP Govt. Medical College, Kangra at Tanda (HP) India \\ ${ }^{2}$ Dept of Dermatology, Dr RP Govt. Medical College, Kangra at Tanda (HP) India
}

\begin{abstract}
Basosquamous carcinoma (BSC) is a rare subtype of basal cell carcinoma (BCC) with an incidence of $1-2 \%$. BSC is characterized by aggressive nature in terms of poor prognosis and distant metastasis. Unlike BCC which is a rodent ulcer with local invasion and no distant metastasis. BSC is usually diagnosed on histopathology examination after biopsy. We hereby present a case report of diagnosis of BSC on cytological examination followed by confirmation with histopathology. To the best of our knowledge, there is the first case reported in literature on this matter. We emphasize the importance of thorough cytological examination so as to suspect and finally confirm this rare entity.
\end{abstract}

\section{Keywords: Basosquamous Carcinoma, Nose, Cytology, Diagnosis}

\section{Introduction}

Basosquamous carcinoma (BSC) is a rare variant of basal cell carcinoma (BCC) with incidence of only $1-2 \%$ cases.

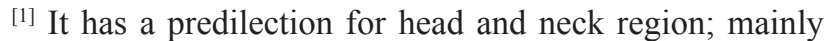
affecting nose, auricular and peri-ocular areas. Unlike $\mathrm{BCC}, \mathrm{BSC}$ is more aggressive and has a tendency towards local invasion and distant metastasis. ${ }^{[2]}$ This terrible property of BSC endangers the life of the patient if is not timely diagnosed. Histopathological features of this rare entity have been well discussed in literature. ${ }^{[1-5]}$ But there is scarcity of information on the cytological features of BSC. We have not come across a single case in literature discussing the cytological features of BSC.To the best of our knowledge, this is the first case report discussing the characteristic cytological features of BSC which helped us to clinch the diagnosis.

\section{Case Report}

A 70 year old male presented in outpatient department with swelling on tip of nose. Swelling was painless with history of bleeding from the swelling. On gross examination, the swelling was $(3 \times 3 \times 2) \mathrm{cm}$ with overlying skin showing bleeding spots. Patient was advised fine needle aspiration cytology (FNAC).Aspiration from the swelling yielded blood mixed aspirate. Smears prepared from the aspirate were hyper-cellular with two types of cell population. The predominant cell population was that of basaloid cells. These cells were arranged in clusters and in isolation with round to oval nuclei and fine chromatin, inconspicuous nucleoli and scant cytoplasm (figure 1 [a]). In addition, a second population of cells was identified. These cells showed moderate pleomorphism, hyperchromatic nuclei, irregular nuclear membranes, inconspicuous nucleoli and mild to moderate deep basophilic cytoplasm (figure 1 [b]). Background shows numerous bare nuclei, foreign body giant cells and stromal fragments. Based on the cytological and clinical findings, a malignant tumor possibly "basosquamous carcinoma" was diagnosed and surgical excision was advised. The surgical excision of the swelling with wide resection margins was performed. Grossly, the excised mass measured $(3 \times 3 \times 2) \mathrm{cm}$. Skin aspect show rough surface. Cut section was grey white and firm. Grossly, the resection margins were free from the grey white growth. A four quadrant sectioning was performed. On histopathology, the lesion consisted of many lobules of tumor cells in the dermis with peripheral palisading of the cells. At places, the lobules showed retraction artefacts (figure 1[c]). Peripheral cells showed mild pleomorphism, coarse nuclear chromatin and scanty cytoplasm. Remaining cells were polygonal in shape with hyper-chromatic nuclei, inconspicuous nucleoli and moderate cytoplasm. At places, keratin pearls were also noted (figure $1[\mathrm{~d}]$ ). All the resection margins were free of tumor. These histological features confirmed the diagnosis of "basosquamous carcinoma”.

\section{Discussion}

$\mathrm{BCC}$ is one of the most common skin malignancies. It is a slow-growing tumor which is locally invasive and nonmetastasizing. ${ }^{[6,7]}$ On the other hand, BSC, a subtype of $\mathrm{BCC}$, is aggressive with tendency to distant metastasis. [2] Basosquamous carcinoma (BSC) is a rare variant of basal cell carcinoma (BCC) with incidence of only 1-2\% cases. It has a predilection for head and neck region; 


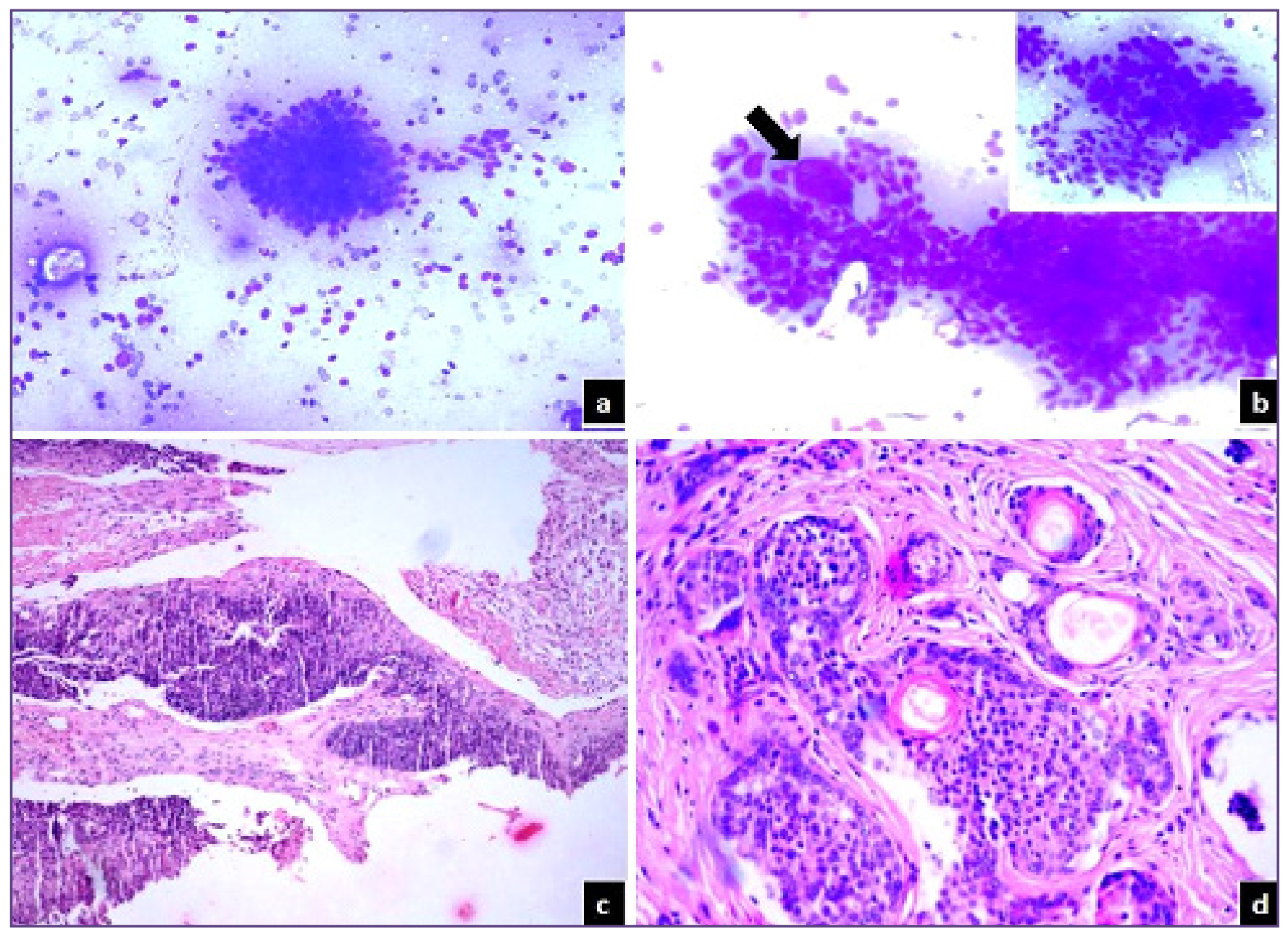

Fig. 1 [a]: Cytology smear showing basaloid cell cluster with high $\mathbf{n} / \mathbf{c}$ ratio, minimal pleomorphism and peripheral palisading; [b]: Cytology smear showing admixed population of highly pleomorphic cells (arrow) \& basaloid cells (inset: cluster of second population of highly pleomorphic cells with $\mathbf{n}$ /c ratio and moderate basophilic cytoplasm); [c]: Histopathology showing basaloid cell clusters with retraction artifact; [d]: Histopathology showing squamoid population with keratin pearl formation.

mainly affecting nose, auricular and peri-ocular areas. ${ }^{[1]}$ Unfortunately, BCC also affects at similar locations and confuse the diagnosis. Prognostically, it is important to distinguish between BCC and BSC.In majority of cases, $\mathrm{BSC}$ has been diagnosed on biopsy and histopathological features have been discussed in detail. ${ }^{[1-5]}$ The cytological features have not been discussed much before. To the best of our knowledge, this is the first case report discussing the characteristic cytological features of this rare entity. FNAC smears of the present case were highly cellular. The predominant cell population was that of clusters and scattered population of basaloid cells. These cells showed high N/C ratio, regular nuclear chromatin, fine nuclear chromatin, inconspicuous nucleoli and scanty cytoplasm. At many places, these basaloid cells were showing peripheral palisading. Cellular smears with mainly basaloid cells in a nose swelling suggest many differentials that include- BCC or adnexal tumors like cutaneous cylindroma and eccrine spiradenoma. But the highlight of this case was a second population of cells. These cells showed moderate pleomorphism, irregular nuclear membranes, hyperchromatic nuclei, inconspicuous nucleoli and mild to moderate deep basophilic cytoplasm. These tumor cells were suggestive of squamoid morphology. Based on these features a diagnosis of a malignant neoplasm possibly Basosquamous carcinoma was extended. Histopathology showed the characteristic feature of BSC that includes areas with features of basal cell carcinoma (basaloid nests with peripheral palisading and surrounded by retraction artefacts) and areas with features of squamous cell carcinoma (squamoid cells with hyperchromatic nuclei and moderate cytoplasm and keratin pearl formation). 
This case highlights the importance of proper microscopic evaluation of slides as the identification of a minor component of squamoid cells in the presence of predominant basaloid cell population helped us to reach the diagnosis.

\section{Conclusion}

To conclude, $\mathrm{BSC}$ is a rare subtype of $\mathrm{BCC}$ with aggressive clinical behavior and poor prognosis. Hence, it is important to distinguish BSC from its close differential BCC. $\mathrm{BSC}$ can be diagnosed on FNAC based on these unique cytological features. Further, this case highlights the importance of thorough microscopic examination of slides so as to clinch this rare diagnosis which could have been otherwise missed on cytology.

\section{Reference}

1. Wermker K, Roknic N, Goessling K, Klein M, Schulze HJ, Hallermann C. Basosquamous carcinoma of the head and neck: clinical and histologic characteristics and their impact on disease progression. Neoplasia. 2015 Mar;17(3):301-5
2. De Stefano A, Dispenza F, Petrucci AG, Citraro L, Croce A. Features of biopsy in diagnosis of metatypical basal cell carcinoma (Basosquamous Carcinoma) of head and neck. Otolaryngol Pol. 2012 Nov-Dec;66(6):419-23

3. Garcia C, Poletti E, Crowson AN. Basosquamous carcinoma. J Am Acad Dermatol. 2009 Jan;60(1):137-43

4. Linton OR, Moore MG, Brigance JS, Gordon CA, Summerlin DJ, McDonald MW. Prognostic significance of basaloid squamous cell carcinoma in head and neck cancer. JAMA Otolaryngol Head Neck Surg. 2013 Dec;139(12):1306-11

5. Fritsch VA, Gerry DR, Lentsch EJ. Basaloid squamous cell carcinoma of the oral cavity: an analysis of 92 cases. Laryngoscope. 2014 Jul;124(7):1573-8

6. Verkouteren JAC, Ramdas KHR, Wakkee M, Nijsten T. Epidemiology of basal cell carcinoma: scholarly review. $\mathrm{Br}$ J Dermatol. 2017 Aug; 177(2):359-372

7. Dessinioti C, Antoniou C, Katsambas A, Stratigos AJ. Basal cell carcinoma:what's new under the sun. Photochem Photobiol. 2010 May-Jun;86(3):481-91

*Corresponding author:

Dr Manupriya Sharma, MD, DNB, Assistant Professor, (Pathology)

Dr RPGMC Kangra, Tanda (HP). Set No. 112, Vivekanand Hostel, Dr RPGMC, Kangra HP, India: 176001

Phone: +91 8628000105

Email: manupriya.priyasharma@gmail.com

Date of Submission : 12.09.2017

Date of Acceptance : 01.10.2017

Financial or other Competing Interests: None.
Date of Publication : 13.01.2018 